\title{
La etimología
}

como gesto

glotopolítico.

El caso del

Diccionario

etimológico del

castellano usual

(1931-1938) de

Leopoldo Lugones

Daniela Lauria

Doctora en Letras (área

Linguística) y magíster en Análisis

del Discurso por la Universidad

de Buenos Aires. Investigadora

adjunta del CONICET.

Profesora de Semiología y del área de Lingüística (grado y posgrado)

en la Universidad Pedagógica

Nacional (UNIPE).

Contato: danielalauria76@gmail.

com

Argentina 


\section{PALABRAS CLAVE:}

Diccionarios; etimología; indigenismos; Leopoldo Lugones; década del 30 en la Argentina.

KEYWORDS: Dictionaries; Etymology; Indigenisms; Leopoldo Lugones; 30's in Argentina.
Resumen: Este artículo se centra en el Diccionario etimológico del castellano usual de Leopoldo Lugones (1931-1938) con el objetivo de dilucidar su posición sobre la lengua, en particular a partir de su propuesta lexicográfica, caracterizada por el énfasis puesto en el componente etimológico. El proyecto de Lugones participa en las intensas disputas que se suscitaron en el campo intelectual argentino de fines del siglo XIX y comienzos del XX en torno a las representaciones culturales. En particular, se pondrá el foco en las polémicas respecto de la cuestión de la lengua y la controvertida idea de formación de un "idioma de los argentinos". La impugnación de varios de los criterios adoptados por ciertos diccionarios de regionalismos, indigenismos, americanismos o nacionales, a partir de la disruptiva modalidad lexicográfica fundada en la etimología, cobra sentido histórico en el marco de las nuevas condiciones políticas (pero también económicas, sociales, culturales y demográficas) que tuvieron lugar a partir de 1930 como consecuencia del primer solpe de estado en el país.

Abstract: This paper focuses on Leopoldo Lugones' Diccionario etimolósico del castellano usual (1931-1938) with the aim of elucidating its position on languase, in particular from its lexicographic proposal, characterized by the emphasis placed on the etymological component. The project of Lusones participates in the intense disputes that arose in the Argentinian intellectual field in the end of the 19th century and beginning of the 20th around cultural representations. In particular, the focus will be on controversies regarding the issue of language and the controversial idea of forming a "idioma nacional de los argentinos". The challenge of several of the criteria adopted by certain Regionalisms, Indigenisms, Americanisms, and National dictionaries, based on the disruptive lexicosraphic modality founded on etymology, takes on historical meaning in the context of the new political conditions (but also economic, social, cultural and demographic) that took place from 1930 on as a result of the first coup d'état in the country. 
La etimología como gesto glotopolítico. El Caso del DiCCIONARIO ETIMOLÓGiCo DEL CASTELLANO USUAL (I93 I-I938) De LeOpoldo

\section{INTRODUCCIÓN}

Adoptar el enfoque glotopolítico implica desentrañar la dimensión política de las intervenciones en el espacio público del lenguaje que tienden a establecer (reproducir o transformar) un determinado orden social y que construyen, para ello, los imaginarios colectivos necesarios en cada instancia histórica, útiles a los intereses de determinado proyecto de índole siempre más amplia (Arnoux, 2008 y Del Valle, 2015). Entre los variados materiales del archivo histórico, tanto pasado como actual que se abordan, los instrumentos lingüísticos en general y los diccionarios en particular ocupan un lugar relevante. Desde esta perspectiva de indagación crítica, las obras lexicográficas, que resuelven en cada caso y transitoriamente una compleja articulación de múltiples factores en juego: opciones teóricas y políticas en la definición de lengua (y de norma lingüística) ligadas a los avances en la reflexión sobre las ciencias del lenguaje; transformaciones en la composición de la población debido, sobre todo, a movimientos migratorios; cambios en la distribución de las fuerzas políticas; requerimientos sociales y económicos; necesidades del mercado laboral; consideraciones pedagógicas vigentes; demandas educativas; desarrollos de las tecnologías de la palabra, etc., son consideradas más que instrumentos metalingüísticos de descripción y/o prescripción que establecen normas, fijan un estándar, definen el léxico y proponen una forma ortográfica; son, en realidad, dispositivos que, en general, manifiestan formas de poder y dominación. Acarrean, por ende, desigualdad ya que legitiman y reproducen principios y valores hegemónicos que se imponen y que regulan las relaciones entre distintos grupos sociales. Esto obedece, claro está, a que son confeccionados 
mayoritariamente por las clases dirigentes puesto que son ellas las que poseen los recursos simbólicos y materiales para hacerloํ.

Este trabajo se centra en el Diccionario etimológico del castellano usual de Leopoldo Lugones (1931-1938) con el objetivo de dilucidar su posición sobre la lengua, en particular a partir de su propuesta lexicográfica, caracterizada por el énfasis puesto en el componente etimológico, en el marco de ciertas condiciones políticas (pero también económicas, sociales, culturales, educativas, laborales y demográficas) como las que se generaron luego de 1912 con la sanción de la Ley Sáenz Peña ${ }^{2}$ y que cambiaron abruptamente después del primer golpe militar en la Argentina en 1930. Tal como mostramos en trabajos previos (Lauria, 2011, 2012 y 2015), distintas condiciones de producción forjan nuevas modalidades diccionarísticas, es decir, nuevas formas de representar la lengua, en particular, a partir del léxico. En ese sentido, la elaboración de un instrumento lingüístico implica siempre la construcción de una lengua y de un saber acerca de ella. Esto no significa, sin embargo, que se manifieste una relación lineal y directa entre el discurso lexicográfico y el contexto. Por el contrario, el diccionario enlaza un entramado de distintas

1 Es importante señalar que en algunos (pocos) casos, los diccionarios acompañaron procesos que, sin llegar a ser revolucionarios o contra hegemónicos, transformaron algún aspecto de la sociedad como, por ejemplo, fueron útiles a reformas pedagógicas que mejoraron las tasas de alfabetización o a la revitalización de lenguas minorizadas como son las lenguas indígenas en los Estados nacionales modernos de América Latina.

2 La Ley Sáenz Peña fue sancionada por el Congreso de la Nación Argentina en 1912. La norma estableció el voto universal, secreto y obligatorio para los ciudadanos argentinos, nativos o naturalizados, mayores de 18 años de edad, que habitaban en el país y que estuvieran inscriptos en el padrón electoral. 
La etimología como gesto glotopolítico. El Caso del Diccionario etimológico del CASTELLANo USUAL (I93 I-I938) De Leopoldo LUGONES

temporalidades y es en los distintos dominios que lo componen (bloque paratextual programático, macroestructura y microestructura) donde se detectan, a partir de un abordaje discursivo, las huellas que remiten a sus condiciones de producción, así como se localizan los puntos de evocación de ciertos lugares de la memoria y que, en conjunto, revelan el sentido histórico y la función social de cada repertorio en el largo proceso de diccionarización de una determinada variedad lingüística.

\section{EN TORNO A LEOPOLDO LUGONES Y SU POSICIONAMIENTO GLOTOPOLÍTICO}

Leopoldo Lugones (Córdoba, 1874 - Buenos Aires, 1938) fue un integrante crucial del campo literario e intelectual argentino entre fines del siglo XIX y las primeras décadas del XX. Fue extremadamente prolífico y escribió en casi todos los géneros (poesía, narrativa, ensayo) y sobre los más variados temas. A lo largo de su trayectoria política, se produjeron varios virajes ideológicos que van de un temprano socialismo, pasando por el liberalismo, el conservadurismo, hasta terminar muy próximo al fascismo (López, 2004). Cabe destacar, además, que tuvo una extensa carrera de funcionario público en el área educativa. Se desempeñó como inspector de enseñanza secundaria, como inspector general de enseñanza secundaria y normal, y fue director de la Biblioteca Nacional de Maestros desde 1915 hasta su suicidio en febrero de 1938.

Las intervenciones de Lugones, como parte de la élite letrada profesional, buscaron diseñar, en varios momentos de su vida, los programas culturales 
vigentes. Concretamente, en la década de 1910 participó del nacionalismo cultural proponiendo una imagen del ser nacional que pudiera influir en las representaciones identitarias promovidas desde la esfera estatal. De acuerdo con el historiador Fernando Devoto (2005), Lugones fue uno de los "inventores de la tradición" mediante un proyecto que anclaba, con matices, en la revalorización de la figura del gaucho.

En la década siguiente, incorporó a dicha propuesta una arenga que proclamaba el reemplazo urgente del proyecto político liberal por uno autoritario y corporativista. De este modo, para Oscar Terán (2008), el giro ideológico de Lugones se basa fundamentalmente en la crítica a la democracia liberal, expresada a través de la Ley Sáenz Peńa sancionada en 1912 y que cuatro años después llevaría a la presidencia a Hipólito Yrigoyen, candidato de la Unión Cívica Radical, principal fuerza opositora del Partido Autonomista Nacional, que había dominado la vida política del país entre 1874 y 1916.

Desde mediados de los años veinte, con su célebre discurso pronunciado en ocasión del centenario de la batalla de Ayacucho (Lima, 1924) en el que convocaba a las Fuerzas Armadas para que directamente se hicieran cargo del papel dirigente en el orden político ("Ha sonado otra vez, para bien del mundo, la hora de la espada”3), Lugones se convirtió en un referente clave del nacionalismo autoritario, antidemocrático y militarista ${ }^{4}$.

3 Disponible en: <https://cdn.educ.ar/repositorio/Download/file?file_id=2128ad00-e9ec-44609d94-8cc381a137b2>.Acceso 22 de nov. 2018.

4 Ver Funes (2006). 
La etimología como gesto glotopolítico. El CASo del DiCCIONARIO ETIMOLÓGiCo DEL CASTELLANO USUAL (I93 I-I938) De LeOPOLdo

Su posición sobre la lengua se expone en diferentes lugares textuales (poemas, ensayos, artículos periodísticos) y en varios momentos (período modernista, conmemoraciones del Centenario de la Revolución de Mayo, década del veinte, últimos años de su vida), como lo mostró Bentivegna (2017 y 2018) en sus rigurosos trabajos dedicados a analizar la posición glotopolítica del autor. Resulta interesante detenerse en dos obras, anteriores al Diccionario etimológico, ya que iluminan sus ideas sobre el lenguaje y las lenguas históricas en general, y sobre la cuestión de la "lengua nacional” en particular. El primer fragmento está tomado de su ensayo Didáctica de 1910:

La inmigración cosmopolita tiende a deformarnos el idioma con aportes generalmente perniciosos, dada la condición inferior de aquella. Y esto es muy grave, pues por ahí empieza la desintegración de la patria. La leyenda de la Torre de Babel es bien significativa al respecto: la dispersión de los hombres comenzó por la anarquía del lenguaje (Lugones, 1979, 285)5.

Como se observa en el pasaje referido, Lugones adhiere a varios tópicos característicos del nacionalismo lingüístico de la época: 1) la lengua es un componente esencial de la nación ("patria”), 2) el monolingüismo y la cultura lingüística monoglósica son la regla en los Estados nacionales modernos y 3) resulta necesario intervenir en el terreno de la lengua.

La segunda cita corresponde al ensayo El payador publicado en 1916, en el que retrata la vida y las costumbres del gaucho en la pampa. Este texto reúne un compendio de conferencias públicas que Lugones ofreció sobre

5 En adelante, todas las citas reproducen la ortografía original. 
el Martín Fierro de José Hernández en el Teatro Odeón de Buenos Aires, tres años antes de que se editaran en libro. Allí, la principal operación argumentativa del autor reside en hacer derivar al gaucho (y, por extensión, su lengua, su vocabulario) del pasado clásico grecolatino. En lo que atañe a la cuestión lingüística, no solo comienza su razonamiento con una advertencia etimológica en torno a las voces payador y payada, a las que inscribe en una genealogía que se remonta a un origen provenzal, sino que además destina el capítulo VI a la descripción de los principales rasgos del lenguaje del poema. Es justamente en esta sección en la que anticipa uno de los tópicos polémicos a partir de los cuales se interpretará el gesto de elaboración de un diccionario de tipo etimológico en el cuadro de la historia política de la lexicografía en la Argentina:

El patriotismo regional ha poblado nuestra literatura de vocabularios que asignan al lenguaje campesino una abundante filiación indígena. Según pertenezcan los autores al Norte o al Sur de la República, aquella resulta quichua, calchaquina o guaraní. Nadie se ha preocupado de analizar comparativamente el castellano de los gauchos con las lenguas afines habladas por los europeos que formaron su ascendencia predominante; pero es seguro, y el lector va a apreciarlo enseguida, que las lenguas maternas de aquellos aventureros, más decididos por ellas cuanto más incultos eran, formaron casi enteramente su caudal (Lugones, 1916, 99).

La operación retórica de Lugones se asienta en criticar varios de los diccionarios de regionalismos que circulaban entre fines del siglo XIX y comienzos del XX, adjudicándoles un carácter poco científico y refutando la idea de que el léxico regional proviene primordialmente de las lenguas indígenas americanas. 
La etimología como gesto glotopolítico. El Caso del Diccionario etimológico del CASTELLANo USUAL (I93 I-I938) De Leopoldo LUGONES

\section{DICCIONARIOS Y GLOTOPOLÍTICA}

Existen varias líneas teóricas que abordan la dimensión ideológica de los instrumentos lexicográficos. La propuesta de la Historia de las Ideas Lingüísticas (Auroux, 1992) es retomada por una serie de investigadores franceses, quienes se centran en estudiar el objeto diccionario desde una mirada discursiva. Los trabajos de Mazière (1986), Collinot y Mazière (1997) y Branca-Rosoff (1995 y 1997), entre otros, analizan la construcción del discurso lexicográfico en coyunturas específicas: examinan, por ejemplo, artículos asociados a distintos campos temáticos (religión, política, ciudad/ campo, etc.). Observan, así, el carácter histórico e ideológico de los sentidos de determinadas voces. Sus contribuciones también ofrecen un análisis detallado de los prólogos, y de los distintos tipos (según el formato y el contenido) y de las diversas funciones que pueden asumir los ejemplos y las citas que comportan los diccionarios.

En Brasil, un grupo de investigadores nucleados alrededor de Eni Orlandi de la Universidade Estadual de Campinas continúan con la tradición iniciada por Collinot y Mazière de analizar discursivamente el diccionario. Autores como Nunes (2002 y 2006), Medeiros (2012), Petri (2012), Celada, Costa \& Brianezi (2015) inscriben sus trabajos en la propuesta materialista del Análisis del Discurso (en particular, en la propuesta de Pêcheux). Esta corriente persigue analizar la cuestión de la lengua en países que se desprenden del peso de un pasado colonial y en los que, en consecuencia, se trasplantó la lengua de sus ex metrópolis, atendiendo esencialmente a su propia historicidad. Para ellos, los diccionarios 
no solo tienen una función normativizadora, sino que su finalidad es principalmente simbólica. De ahí que los proyectos sobre la lengua sean correlativos a determinados proyectos de unidades políticas (naciones, regiones, imperios, áreas transnacionales).

Desde la perspectiva del Análisis Crítico del Discurso, investigadoras españolas como Forgas Berdet (2007) y Rodríguez Barcia (2008, 2010 y 2012) se ocuparon de examinar el componente ideológico en repertorios del mundo hispánico, especialmente en las definiciones y en los ejemplos de uso de las distintas ediciones del Diccionario de la Real Academia Española $(D R A E)$.

En lo que respecta al estudio de los diccionarios etimológicos, se cuenta con aportes provenientes sobre todo de la Historiografía Lingüística y de la Metalexicografía que desarrollan descripciones de la historia de dicho género lexicográfico desde las obras precursoras (con foco en Covarrubias y Alderete) hasta la actualidad (Alvar, 2016 y Carriazo Ruiz, 2017,) antes que explicaciones políticas o ideológicas sobre la presencia de reflexiones en torno al origen de las voces recopiladas.

Como ya se esbozó en la introducción, el presente artículo adopta un enfoque glotopolítico. Arnoux (2008) y Del Valle (2015) definen la Glotopolítica como el estudio que aborda las intervenciones y prácticas en el espacio público del lenguaje, atendiendo a la relación que estas entablan con requerimientos socio históricos siempre de orden más general. Los trabajos que se realizan desde esta perspectiva acentúan el carácter interpretativo de las investigaciones. De ahí que se lo articule con el Análisis del Discurso (Arnoux, 2006) como herramienta que provee la construcción de un dispositivo de análisis acorde a 
La etimología como gesto glotopolítico. El Caso del DiCCIONARIO ETIMOLÓGiCo DEL CASTELLANO USUAL (I93 I-I938) De LeOpoldo LUGONES

los materiales y a los objetivos planteados. En ese sentido, se enfocan los textos no solo como documentos, siguiendo el camino habitual (instrumental) del estudio de las políticas lingüísticas, sino que se los aborda como discursos, lo que conduce a una actividad interpretativa que conjuga lenguaje e historia a partir de múltiples remisiones a las condiciones de producción a través del reconocimiento y de la descripción, en la materialidad significante, de determinados rasgos lingüístico-discursivos, que configuran procesos de sentidos, a partir de regularidades, vacilaciones o desplazamientos, que se comentan como huellas de esos procesos históricos y que están cargados de ideología. En suma, los diccionarios constituyen, pese al hecho de que, en la larga duración, presentan una notable homogeneidad genérica, discursos donde se asoman y se esconden sistemas lingüístico-político-histórico-ideológicos, que participan desde la reflexión sobre el lenguaje en la constitución de las subjetividades que las sociedades requieren.

Metodológicamente, se examinan los diversos dominios que componen el discurso lexicográfico, en especial las zonas más sensibles a las condiciones de producción puesto que son expresión de posicionamientos políticos situados. El análisis del discurso se centra, por un lado, en los elementos megaestructurales (títulos, prólogos, advertencias, notas, apéndices, guías de uso) con el objeto de examinar el bloque programático, el dispositivo enunciativo y las orientaciones retórico-argumentativas. Por otro, se explora la selección de la macroestructura (la lista de voces recopiladas) y el tratamiento de la microestructura (las informaciones que siguen a la entrada: enunciados definidores, descriptores gramaticales y marcas de uso, citas y ejemplos, orden 
de las acepciones, observaciones etimológicas y enciclopédicas, indicaciones sintagmáticas y paradigmáticas, entre otras).

\section{El Diccionario etimológico del Castellano usual (1931-1938)}

El Diccionario etimológico del castellano usual de Leopoldo Lugones inaugura un género lexicográfico en la Argentina. En efecto, la obra, sustentada en ciertos saberes científicos filológicos y lingüísticos legitimados de la época, es el primer (y uno de los pocos) diccionario etimológico realizado en el país.

\subsection{Descripción de la obra}

El diccionario consta de varias secciones: un prólogo y una advertencia firmados por el autor; un apartado sobre fuentes lexicográficas consultadas; el listado de abreviaturas empleadas y una serie de artículos que no completan siquiera la letra A (de "a" hasta "arronzar"). Lugones menciona nueve diccionarios que actúan como filiaciones teóricas explícitas ${ }^{6}:$ Diccionario Enciclopédico de la Lengua Castellana de Elías Zerolo, Diccionario Etimológico de la Lengua Castellana de Pedro F. Monlau, Manual Greco-Latino Español de P. P. Escolapios, Glosario Etimológico de Leopoldo de Eguilaz, Vocabulario Español-Arábigo de José Lerchundi, Dicionário da Lingua Portuguesa de Cándido de Figueredo, Dizionario Universale della Lingua Italiana de P. Petrocchi, Dictionnaire de la Langue Française de E. Littré y Webster's

6 A propósito, cfr. el concepto de horizonte de retrospección en Auroux (2008). 
La etimología como gesto glotopolítico. El CASo del DiCCIONARIO ETIMOLÓGiCo DEL CASTELLANO USUAL (I93 I-I938) De LeOPOLdo LugONES

Universal Dictionary, aunque en el cuerpo del texto, cita (y refuta) otros repertorios en general de "americanismos" o nacionales como, por ejemplo, el Vocabulario rioplatense razonado de Daniel Granada (1889/1890), el Diccionario argentino de Tobías Garzón (1910), el Diccionario etimológico de las voces chilenas derivadas de lenguas indigenas americanas de Rodolfo Lenz (1905-1910) y varios de chilenismos, mexicanismos, hondureńismos, entre otros. Entre las obras sobre el bajo latín citadas, figuran Glossarium Medice et Infimac Latinitatis, edición de Leopoldo Favre, Cantar del Mio Cid (vocabulario) y Orígenes del Español de Ramón Menéndez Pidal, y la Introducción a la Lingüistica Romance de Wilhelm Meyer-Lübke (en la traducción de Américo Castro).

Solo dos notas respecto a la Advertencia. Primero, explicita la intertextualidad con la decimoquinta edición del $D R A E,{ }^{7}$ al que en el prólogo califica como el "más difundido y autorizado" (Lugones, 1944, 7) y al que, no obstante, corrige tanto los enunciados definidores como las marcas etimológicas, además de adicionar voces faltantes y suprimir las arcaicas debido a su carácter de diccionario usual. A propósito, el autor aclara en el prólogo: "debe limitarse [su diccionario] al castellano usual porque el estudio de las voces anticuadas corresponde a la filología” (Lugones, 1944, 7). Segundo, puntualiza que clasifica las etimologías propuestas en dos clases: las definitivas y las condicionales con su "debida prevención” (Lugones, 1944, 29).

7 Esta edición de 1925 se destaca por dos aspectos: uno, por el cambio de título: pasa de ser Diccionario de la lengua castellana a Diccionario de la lengua española y dos, relacionado con el anterior, porque incluye una gran cantidad de voces americanas, de ahí que se la conozca como la "edición americana". 


\subsection{Condiciones de circulación de la obra: la prensa educativa}

El diccionario tuvo dos ediciones: la primera se publicó por entregas entre noviembre de 1931 y febrero de 1938 en El Monitor de la Educación Común ${ }^{8}$, órgano de difusión oficial del Consejo Nacional de Educación creado en 1881. La segunda fue publicada en 1944 por la Academia Argentina de Letras en un solo tomo de 622 páginas. Esta edición le agrega a la original una advertencia preliminar sobre el carácter incompleto de la obra.

A fines del siglo XIX, las publicaciones periódicas poseían un peso importante en la vida pública del país. En el ámbito educativo, debido a las limitaciones del mercado editorial, de las bibliotecas y de las posibilidades de los maestros para acceder a los libros, la revista El Monitor de la Educación Común fue un medio central para (in)formar a los docentes. Pero, naturalmente, tuvo otras funciones políticas. La revista, fundada por Domingo Faustino Sarmiento cuando era superintendente general de escuelas y editada por el Consejo Nacional de Educación por mandato de la ley 1420 a partir de 1884, tiene una extensa vida dividida en varios períodos (1881-1949, 19591961, 1965-1976, 2000-2001, 2004) ${ }^{9}$. Estaba destinada a intervenir en el

8 La revista se puede consultar digitalmente en http://www.bnm.me.gov.ar. Agradezco algunos datos de las características de la publicación en la década del treinta a Mariana Alcobre. Cfr. Alcobre (2017).

9 Antes de 1884 fue editada por la Comisión Nacional de Educación. La perdurabilidad de la revista obedece a su carácter de publicación oficial (no comercial), aunque cabe señalar que, en algunas épocas, llegó a incluir publicidades (de muebles, enciclopedias, instrumentos musicales como pianos) para su financiamiento. Estas publicidades daban cuenta del perfil social y cultural del magisterio, así como del lugar que esta profesión ocupaba en la sociedad y/o de las expectativas y aspiraciones sociales que tenían quienes a ella se dedicaban. 
La etimología como gesto glotopolítico. El Caso del DiCCIONARIO ETIMOLÓGiCo DEL CASTELLANO USUAL (I93 I-I938) De LeOpoldo LUGONES

campo pedagógico, difundiendo la opinión oficial en torno al proyecto educativo nacional, en especial sobre temas relativos a la enseñanza primaria con el fin de establecer los parámetros de la nacionalidad y la ciudadanía. Desde el primer ejemplar, la publicación de aparición mensual, que llegaba gratuitamente a la red de escuelas primarias estatales (de gestión pública) de todo el país, tuvo dos objetivos centrales: difundir las resoluciones de las autoridades nacionales destinadas a la organización del sistema educativo y contribuir a la instrucción del personal docente. Estas dos metas se expresaron en la estructura textual organizativa de la revista: por un lado, una sección se reservó a la trascripción de las actas del Consejo y a otra serie de documentos como documentos oficiales, datos estadísticos, informes de autoridades, y discursos de directores y maestros. Por otro lado, las restantes secciones se dedicaron a la difusión de noticias de especialistas del país y del exterior, columnas de opinión, reseñas bibliográficas, traducciones de libros y artículos de revistas extranjeras, notas literarias e históricas y panoramas de situación de lo que acontecía en otras regiones.

A fines de 1920 y comienzos de 1930, El Monitor expresó la importancia que adquirieron las corrientes nacionalistas y tradicionalistas en el campo educativo, que venían siendo fuertes desde el Centenario con los cambios de planes de estudio y que en esa época se hicieron más evidentes e intensas. En este período, autores como Ernesto Quesada, Carlos Ibarguren, Enrique Banchs, e, incluso, el propio primer presidente de facto José Félix Uriburu, publicaron en sus páginas, divulgando la nueva matriz ideológica antiliberal que predominó en la política argentina con fuerza luego del golpe militar. 
En lo que atańe a la lengua nacional (su concepción, alcance y limitaciones), esta publicación abordó el tema desde sus inicios, por su importancia en la configuración de la nacionalidad. Pruebas de esto, se ven en el estudio de la historiadora Bertoni (2001) para la primera época y en el trabajo de Di Tullio (2003), quien examinó detalladamente la revista entre 1880 y 1930 y concluyó que constituye una fuente documental valiosa ya que permite rastrear las políticas educativas que se implementaron y las ideas que subyacen a los distintos métodos de enseñanza de la lengua a lo largo de ese período.

Lugones era un asiduo colaborador del Monitor de la Educación Común desde 1908, sobre todo de informes y comentarios diversos debido a su cargo de inspector de enseñanza, pero también de ensayos más extensos como es el caso, ya referido, de la Didáctica de 1910, que también apareció por entregas en varios números. Se trata, entonces, por el medio en el que aparece y circula, de un material dirigido a los maestros de escuelas primarias. Para que su comprensión resultara sencilla, el autor señala que no emplea tecnicismos (pese a que en los artículos sí lo hace al hablar de "epéntesis", "prótesis", “metátesis", entre otros fenómenos ligados al cambio lingüístico), que translitera los alfabetos griego y árabe y que utiliza pocas e imprescindibles abreviaturas.

\subsection{El diccionario en la historia de la lexicografía argentina}

Desde la historia de la producción lexicográfica monolingüe del español de la Argentina-en la mitad del siglo XIX-, pueden vislumbrarse diversas 
La etimología como gesto glotopolítico. El CASo del DiCCIONARIO ETIMOLÓGiCo DEL CASTELLANO USUAL (I93 I-I938) De LeOPOLdo LugONES

formas diccionarísticas que asumió (y asume) el proceso de diccionarización. Cada uno de estos actos de intervención sobre el lenguaje se imbrica con específicas condiciones sociohistóricas de producción y circulación, así como comporta orientaciones glotopolíticas precisas. En varias de estas modalidades (ruralismos, indigenismos, regionalismos, barbarismos y argentinismos), el componente etimológico ocupa un lugar en la microestructura, pero en ningún caso es el segmento central del artículo lexicográfico. De hecho, presentan información etimológica el Diccionario filológico comparado de la lengua castellana de Matías Calandrelli (1880-1916), el Tesoro de catamarqueñismos (1898) de Samuel Lafone Quevedo, el Vocabulario rioplatense razonado de Granada, el capítulo IV del libro de Abeille en el que se exploran los neologismos ${ }^{10} \mathrm{y}$, en menor medida, por su criterio asentado en el uso, el Diccionario Argentino de Garzón.

La empresa lexicográfica de Lugones, en cambio, se afirma sobre la codificación etimológica ${ }^{11}$ y, con ello, busca objetar la cientificidad y veracidad de las obras previas. En ese sentido, el autor asevera en el prólogo:

La revisión etimológica del castellano usual es la obra de cultura más importante para los pueblos del habla, ya que uniformado con seguridad

10 Si bien el libro Idioma nacional de los argentinos de Abeille no es un diccionario, el capítulo IV "Neologismo" gira alrededor del léxico y presenta algunos rasgos genéricos propios del discurso lexicográfico como la inclusión de un listado alfabético de voces con sus definiciones, marcas y etimologías.

11 En América, hay dos antecedentes centrales: el Diccionario de construcción y régimen de la lengua castellana de Rufino José Cuervo (iniciado en 1872), que brinda un estudio exhaustivo acerca del origen y la evolución (etimología) del significado, la sintaxis y la ortografía de cada palabra consignada y el Diccionario etimológico de las voces chilenas derivadas de lenguas indígenas americanas de Lenz, en el cual la etimología opera para explicar el sustrato de las lenguas indígenas. 
científica su principal e indispensable órgano de comunicación, alcanzarán doble eficacia el empleo racional de las voces y la consiguiente firmeza de su concepto, logrados así para utilidad de todos (Lugones, 1944, p.7).

En la medida en que a partir de 1920, se institucionalizó el campo del saber lingüístico en el país: en 1923 se fundó el Instituto de Filología de la Universidad de Buenos Aires y en 1931 la Academia Argentina de Letras (Glozman y Lauria, 2012), Lugones creyó necesario apoyarse dispersa pero estratégicamente en los conocimientos provenientes de la etimología en tanto disciplina relacionada con la filología y con la lingüística históricocomparativa que comprende el estudio del origen de las palabras mediante la investigación de su significado "original”, así como de su evolución diacrónica ${ }^{12}$. De acuerdo con Lara (1997), este componente microestructural se convirtió en uno de los valores simbólicos privilegiados y rigió a lo largo del tiempo, con mayor intensidad en ciertas coyunturas, la producción de la lexicografía monolingüe, ya que develaba "el ser de la cosa”, anudaba la reflexión sobre la lengua al de la ontología y proponía la necesidad de que todo discurso sobre las cosas se situara en relación con un significado “verdadero" por originario. La presencia de notas etimológicas confiere, así, veracidad a la información que se presenta y pasa a constituir una propiedad determinante para la configuración de los diccionarios monolingües en las sociedades occidentales modernas monoglósicas (Guiraud, 1979).

12 La lingüística histórico-comparativa había tenido mayor auge a fines del siglo XIX. En los años que Lugones escribe su obra, el Instituto de Filología de la UBA ya adscribía a corrientes sincrónicas y estilísticas. 
La etimología como gesto glotopolítico. El CASo del DiCCIONARIO ETIMOLÓGiCo DEL CASTELLANO USUAL (I93 I-I938) De LeOPOLdo

Nuestro punto de partida radica en que la impugnación de Lugones de varios de los criterios adoptados por ciertos diccionarios de americanismos, regionalismos o nacionales, a partir de la disruptiva modalidad lexicográfica fundada en la etimología, cobra sentido histórico en el marco de las nuevas condiciones que tuvieron lugar desde 1930 como resultado del primer golpe de estado ejecutado por el teniente general José Félix Uriburu con el apoyo de sectores civiles nacionalistas. Con un proyecto político claro, atravesado por una fuerte impronta autoritaria, que buscaba restaurar en el poder el orden conservador, heredero del roquismo, es decir, la oligarquía desplazada unos años antes y que había dominado la política argentina hasta $1916^{13}$, su discurso gravitaba en torno a tres ejes centrales: orden, propiedad y jerarquía. En materia de lengua, la etimología, conforme el planteo de Lugones, va a operar sobre esos mismos ejes.

El gesto de Lugones es una reacción frente al planteo de Abeille en su Idioma nacional de los argentinos de 1900 pero también -y principalmentefrente a otras formas diccionarísticas que circularon antes, durante y después del Centenario de la Revolución de Mayo, incluso con el aval del aparato estatal. Nos referimos a los diccionarios de "ruralismos", "indigenismos", "regionalismos", "barbarismos" y "argentinismos" que participaron de las

13 Una combinación de factores sociales, económicos y políticos tanto internos (fin del modelo agroexportador y, con él, disminución de la inmigración masiva; comienzo del proceso de migraciones internas debido al inicio del proceso de industrialización) como externos (crisis económica mundial, ascenso del fascismo) explican el derrocamiento del presidente constitucional Hipólito Yrigoyen. En ese escenario, Uriburu representaba a quienes venían, desde la década precedente, rechazando los cimientos conceptuales de la democracia representativa. Cfr. Cattaruzza (2009). 
distintas instancias del proceso de diccionarización monolingüe del español de la Argentina ${ }^{14}$. Uno de los blancos predilectos es el Diccionario argentino (1910) de Garzón, su maestro de primeras letras en Córdoba ${ }^{15}$, debido al carácter liberal, flexible, inclusivo y cosmopolita que asume a la hora de incluir vocablos (Lauria, 2011) ${ }^{16}$.

El recurso de la etimología del que echa mano Lugones, de la búsqueda de raíces primigenias, mediante, como se verá más adelante, conexiones más o menos forzadas, opera en dos frentes complementarios: otorga un "fundamento científico", dice el autor en el prólogo (Lugones, 1944, 26), concediéndole objetividad, veracidad y transparencia a los juicios emitidos, por una parte, y comporta un valor simbólico puesto que devela el ser, la esencia (propiedad) de la voz, por la otra. El mecanismo de la etimología

14 En su libro sobre los diccionarios del español de la Argentina, Pedro Barcia (2004) no incluye la obra de Lugones. El hecho de que aparezca "castellano" sin ningún atributo ("nacional", "argentino", "de la Argentina") en el título no invalida su lugar en esa serie textual.

15 Tobías Garzón fue un educador y escritor argentino de ideología liberal. Nació en Córdoba en 1849 y murió en 1914. Durante muchos ańos fue profesor de castellano en el Colegio Montserrat. En cuestiones políticas, apoyó la candidatura y participó en la gestión de Nicolás Avellaneda como presidente del país.

16 En 1910, año en que se publicó el Diccionario Argentino de Garzón, se fundó en Buenos Aires la Academia Argentina de la Lengua por presión de la monarquía española y de la RAE, en concordancia con un sector de la intelectualidad nacional y en relación directa con el Estado, en el marco de los festejos por el Centenario y con una marcada visibilidad de emergencia de posiciones hispanistas. Esta institución proyectó la elaboración de un Diccionario de argentinismos, con un perfil distinto del de Garzón en cuanto a la configuración del léxico nacional. La obra de la AAL se inscribe más cerca de la vertiente nacionalista conservadora. Afín a un hispanismo con cada vez más peso, considera pernicioso tanto el cosmopolitismo como las nuevas manifestaciones lingüísticas criollo inmigratorias, privilegiando un sistema de valores tradicionales basado en los ruralismos, que ancla en una concepción esencialista de la nación. V. Lauria (2017). 
La etimología como gesto glotopolítico. El CASo del DiCCIONARIO ETIMOLÓGiCo DEL CASTELLANO USUAL (I93 I-I938) De LeOPOLdo

redunda así en la no inclusión de las voces "corruptas”, recuperando la pureza (no el purismo) del idioma.

\section{ANÁLISIS}

El análisis se detiene en dos planos: primero, en el prólogo donde el autor expone una narrativa sobre la historia de la lengua castellana que le sirve como plataforma para justificar el recurso de la etimología. Dicho relato, teñido por la dicotomía civilización / barbarie, parte de la tópica del discurso social (Angenot, 2010) de la época, se inicia con el proceso de romanización, pasa por la invasión árabe a la Península y llega a la conquista de América. Luego, se enfoca en una muestra cualitativamente representativa de artículos (Rodríguez Barcia, 2016) ${ }^{17}$. Se trata de los llamados “americanismos”, que son, por lejos, los vocablos (sustantivos) que están sobrerrepresentados numéricamente en la obra, con el fin de observar las regularidades en el esquema argumentativo en el cual se inserta la etimología.

En cuanto al prólogo, un primer argumento radica en asegurar que el castellano muestra una tendencia histórica a la unidad debido a la resistencia que ofrece a la incorporación de voces foráneas. El razonamiento de Lugones se distancia de la posición de la Real Academia Española (RAE) que, según el autor, por influencia de la filología alemana del siglo XIX sobrevalora las raíces góticas ("bárbaras”) y desestima la presencia del árabe en el castellano.

17 En este punto, es necesario realizar una aclaración metodológica: si bien trabajamos con una muestra que no pretende agotar el análisis y sin ánimo tampoco de ser exhaustivos, dicha selección de registros ofrece una visión de conjunto que permite obtener resultados significativos debido a su sistematicidad. 
Siguiendo su reflexión, las raíces latinas son las predominantes, "dadas la difusión, precisión y riqueza” (Lugones, 1944, p.10) del latín primero y del castellano después. Debido entonces a la resistencia del castellano, la invasión germánica tuvo que adoptarlo como propio, lo que condujo a un escaso número de raíces góticas y a la poca influencia de otras lenguas como el vasco. Si bien el árabe no pudo desalojarlo durante los siglos que duró la conquista musulmana, aportó un número notable de raíces, puesto que era un pueblo más “adelantado" (Lugones, 1944, p.9) que el gótico. La contribución griega también se destaca. En cuanto al castellano en América, el autor afirma que lenguas como el azteca, el quichua, el araucano y el guaraní tomaron muchas más voces del castellano que lo que sucedió en la dirección contraria:

[...][Y] para discernir mejor la tendencia patriótica, harto explicable por cierto, en algo tan profundamente nacional como el idioma, basta recorrer los numerosos vocabularios de argentinismos, chilenismos, mejicanismos, etc., para advertir la ciega profusión con que se da como términos de las lenguas indígenas locales -quichua, guaraní, araucano, azteca...- voces castellanas anteriores a la Conquista (Lugones, 1944, p.9).

Como puede apreciarse en el fragmento expuesto, para el autor los llamados americanismos por los planteamientos lexicográficos de -ismos tan profusos en los países americanos entre fines del siglo XIX e inicios del XX son, en verdad, voces cuyo origen geográfico es castellano y cuya datación reenvía a antes de 1492 .

En segundo lugar, Lugones se opone tanto al purismo español, "quimérico" (Lugones, 1944, 25), representado por la RAE como a la corriente que defiende 
La etimología como gesto glotopolítico. El CASo del DiCCIONARIO ETIMOLÓGiCo DEL CASTELLANO USUAL (I93 I-I938) De LeOPOLdo LUGONES

una lengua nacional, a la que califica como "descaminado patriotismo" (Lugones, 1944, 16). Sobre el primer tema, explica que "pureza” y "purismo" no son lo mismo porque la primera significa "respeto al idioma" (Lugones, 1944 , 18), puesto que emplea sus propias palabras y comunica con claridad y precisión; mientras que el segundo puede entenderse como "servilismo académico" (Lugones, 1944, 18), ya que acepta sin discutir los lineamientos de la academia. Desde su punto de vista, las propuestas escolares, y aquí su guiño a los docentes destinatarios de la obra, que se implementaron en el país y fracasaron obedecen al segundo caso en la medida en que son “serviles" (Lugones, 1944, 18).

Sobre el segundo aspecto, el ligado al "idioma nacional", su postura contraria es contundente como queda evidenciado patentemente en las siguientes tres citas:

Tampoco es aceptable el nacionalismo. Emplear un idioma bastardo, sólo porque sea de acá, equivale a incomunicarse en la fealdad y en la pequeñez, cuando la civilización constituye en realidad un sistema de comunicaciones. Cuanto más salvajes son las tribus de una región, más lenguas distintas hablan.

Pero las condiciones de vida en que cada país se desarrolla, influyen sobre su lenguaje. Es lo que diferencia nuestro castellano del peninsular, sin dejar de ser el idioma común, y lo que debemos racionalmente defender cuando ofrezca mayores ventajas (Lugones, 1944, 19).

Toda una escuela de lexicólogos -si tal nombre merece-cultiva por patriotismo esta y las otras manifestaciones de barbarie. Supone que así llegaremos a la creación del idioma propio, tal cual sucedió con los romances derivados del latín. Pero este fenómeno es singular en la historia de las lenguas, porque fue un efecto de las invasiones bárbaras que destruyeron el Imperio Romano. Faltándonos acá la guerra invasora, la incomunicación consiguiente y la 
conquista extranjera, es de sentido común que no sucederá aquello. Y así se advierte. La alteración del castellano en los distintos países de América es insignificante y habrá de serlo cada vez más al solo influjo de la mejor comunicación (Lugones, 1944, 24).

No existe por ventura ni el indicio de la lengua argentina que se supone en formación. Este fenómeno que, de ser real, constituiría una fatalidad lamentable, al reportarnos el aislamiento de una vasta comunidad internacional cuyo crecimiento asegura al castellano una categoría prominente, quizá, entre las lenguas universales, debería inducirnos, por el contrario, a la defensa de tan precioso instrumento comunicativo, lo que es decir elemento de civilización, sin desconocer, por supuesto, la influencia local que todos los idiomas sufren continuamente; aun cuando esto, lejos de acarrear descomposición, es la evolución fundamental de la vida (Lugones, 1944, 25).

En efecto, los pasajes transcriptos dan cuenta de que según el autor la formación de un "idioma nacional" o de una "lengua argentina" no solo es inviable sino que si se produjera sería altamente perjudicial para el país. De este modo, su lógica estriba en mantener la unidad de la lengua castellana, con algunas pocas y controladas diferencias idiosincráticas, en tanto emblema de la civilización. La diversidad de lenguas, por el contrario, expresa la fatalidad y, en última instancia, también la barbarie.

La importancia de la lengua como instrumento de comunicación es el tercer argumento que proporciona Lugones. Un buen idioma es el que entiende la mayor cantidad posible de gente, de ahí su rechazo al "idioma de los argentinos”. El buen idioma no es el académico (el que fomenta el purismo), tampoco el de los libros (escritores), sino aquel utilizado por los sectores cultos. Defender una "lengua argentina" se debe a la demagogia y al hecho de otorgarle a la "plebe una importancia capital en la formación de los 
La etimología como gesto glotopolítico. El Caso del DiCCIONARIO ETIMOLÓGiCo DEL CASTELLANO USUAL (I93 I-I938) De LeOpoldo LUGONES

idiomas" (Lugones, 1944, 25). En definitiva, para el autor, "Todo idioma es obra de cultura realizada por cultos" (Lugones, 1944, 25) y para que no queden dudas "el destino de lo vulgar es perecer con el vulgo" (Lugones, 1944, 25).

Por último, Lugones plantea que reviste sumo interés revisar los llamados americanismos porque son voces que, en algunos casos, no sobrevivieron en España o son acepciones nuevas (Lugones, 1944, 15). Como ya se indicó, conforme su razonamiento, las lenguas indígenas tomaron prestado más del latín y del castellano que a la inversa, lo que lo impulsa a impugnar las etimologías indígenas propuestas, sobre todo, en la mayoría de los diccionarios de -ismos y retomadas en el DRAE. Son, en consecuencia, "falsos americanismos" (Lugones, 1944, 16). Para ejemplificar su idea, remite a la voz "bagual" que el $D R A E$ (así como varios diccionarios que registran el léxico privativo del español de la Argentina, tales como Granada, Abeille, Garzón, entre otros) le otorga origen araucano. Para Lugones, en cambio, el origen es provenzal, el que, a su vez, se remonta al latín y tiene también influencia, "concurrencia" dice el autor en términos técnicos, árabe (Lugones, 1944, 12-13).

La principal tesis de Lugones descansa entonces en que el castellano de América es "quizá más castizo aún (que el de la Península)" (Lugones, 1944, 15), dado que proviene del habla popular de los conquistadores y se conservó, por lo tanto, más genuino, ajeno a la influencia del culteranismo de los escritores del Renacimiento español (Lugones, 1944, 16). Además, por ser popular, estuvo en contacto con voces de origen árabe. Fue ese castellano el que llegó y se instaló en América y el que se impuso sobre las lenguas indígenas "menos flexibles, ricas y propagadas" (Lugones, 1944, 
16), incluso en campos léxicos como la flora y la fauna ya que, sigue el autor, los conquistadores tendieron a designar con "homónimos europeos" (Lugones, 1944, 16) esas realidades. En definitiva, la explicación de los "falsos americanismos" responde a:

El espíritu patriótico que suscitó la independencia, indujo después a invertir la relación, atribuyendo a las lenguas americanas muchos términos, por el hecho de haber caído en desuso peninsular o de no hallarse en el diccionario de la Academia. Esta, a su vez, con un propósito de armonía tan respetable como erróneo, tiende progresivamente a la aceptación de americanismos propuestos por lexicólogos más entusiastas que avisados [...] (Lugones, 1944, 16).

La formulación citada conduce al segundo plano de análisis: observar cómo funciona el componente de la etimología en una serie de artículos que consignan "falsos americanismos". Como muestra, tomamos los siguientes asientos lexicográficos:

abatí. El Dic. da este nombre guaranítico del maíz, como argentinismo anticuado, lo que es inexacto.

acal. Según el Dic., del "mejic. (?) acalli, de atl, agua, y cali, casa. Nombre que los mejicanos daban a la canoa, y en general a cualquier embarcación". Las voces castellanas cala: sentina, y chalana: canoa, derivadas del gr. kálon: leña, madera y nave por extensión (v.) permiten suponer el mismo origen a la voz acal cuya $a$ inicial sería prótesis popular o mozárabe.

acochinar. (s. e. $\mathrm{D}^{18}$.) "tr. fam. Matar a uno que no puede huir o defenderse, o a quien se sujeta para que no se escape ni defienda, como se hace para degollar a los cochinos. 2. fig. y fam. Acoquinar. 3. En el juego de las damas, encerrar un peón de modo que no se pueda mover". Se ve, pues, que el Dic. cree a este verbo derivado de cochino. Pero no hay tal. En sus $1^{\mathrm{a}}$ y $3^{\mathrm{a}}$ aceps.,

18 Significa "Sin etimología en el Diccionario". Se refiere al DRAE. 
La etimología como gesto glotopolítico. El CASo del DiCCIONARIO ETIMOLÓGiCo DEL CASTELLANO USUAL (I93 I-I938) De LeOPOLdo LugONES

trátase de una forma del anticuado aconchar, $2^{\mathrm{a}}$ acep.: "arrimar mucho a cualquier parte una persona para defenderla de algún riesgo o acometida" (v.); pero, las otras cuatro indican el predominio de la significación general de arrimar estrechamente, juntar y estrechar (v.). La etimología que atribuye a este anticuado la Academia: el ital. acconciare, es errónea. Procede del lat. cuncti, cunctus: arrimados, concurrente con jungo, junxi: juntar, unir. De ahí salió el baj. lat. cunciatura: apéndice, complemento aplicado a cualquier cosa, como si dijéramos juntadura, y por extensión aderezo, arreglo, conforme se ve en la primera acep. de aconchar y en las del ital. acconciare. Las otras aceps. se explican todas por juntar, bajo la forma adjuntar que indica a su vez el origen de la $a$ inicial en ambos verbos. Acochinar es, en suma, acorralar, lo que, originariamente, significa reunir animales en un recinto. (v. cochino y cocho). El sinónimo achinar (s. e. D.) es mera contracción vulgar, con probable concurrencia del lat. accingo: ceñir, encerrar (v.) que hizo el baj. lat. accíngere: circundar, rodear. Falta en el Dic. la correspondiente remisión a dicho sinónimo.

achiguarse. "Argent. y Chile. Combarse una cosa; echar panza una persona". Bajo esta última acep. aplícase entre nosotros con preferencia a los animales. Mas, la etimología de dicha voz, va a ofrecernos una sorpresa.

Según el Dic., procede "de $a, 2^{\circ}$ art., y chigua", pero el mismo léxico no consigna esta palabra.Ella existe, sin embargo, en la República Argentina y en Chile, designando en ambos países la armazón de mimbre o ramas con que se refuerza los costales o se reemplaza las árganas; y también el costal cosido. En Chile significa igualmente una especie de zarzo. En Santiago del Estero, trenzarse el pelo es chiguarse; y la trenza delgada de cabello recibe el nombre de chigua o chihua, forma usada también en Chile.

Lenz en su Diccionario etimológico de las Voces Chilenas derivadas de Lenguas Indigenas Americanas, y Román en su Diccionario de Chilenismos, atribuyen como origen de la voz quichua y aimara achíhua: quitasol; pero ella procede de los arábigos chaguál, chiguál: atado, lío; y schil: hilván. En el Vocabulista del P. Alcalá, xíguaq (pronúnciase schíguac) es el plural de xúca (pronúnciase shúca): tela. Trátase a mi ver de una adopción arábigo-espańola del baj. lat. xóca (pronúnciase schóca) que significó velo monjil, y que fué una mera variante de toca por transformación vulgar de la te en tse.

achira. "Voz quichua", según el Dic. "Planta de la América Meridional, de la familia de las alismáceas, hojas ensiformes y flor colorada. Críase en 
terrenos húmedos. 2. Planta del Perú o de la familia de las cannáceas y de raíz comestible. Chile, cañacoro".

El cañacoro, que es también una canácea (v.) vale decir una caña, tiene como todas ellas hojas semejantes a las de la achira: canna glauca, L., y canna coccínea, Mill.: es decir, respectivamente, caña verdosa (por las hojas) y caña escarlata (por las flores). La variedad más común de la achira, tiene, además, hojas purpúreas.

Achira es el nombre que se da en Colombia, Chile, Perú y el Río de la Plata, al balicero o balisero (en fr. balisier) voces que, por cierto, faltan en el Dic. (v.). El balicero es, a su vez, una cańa: arundo indica L.

Pero en la formación de la voz que estudiamos, no hay tal quichua. Su etimología errónea proviene de Tschudi y de Middendorf, quienes en los léxicos que compusieron sobre dicha lengua americana (años de 1853 y de 1890 , respectivamente) le atribuyen ese origen.

Ahora bien, en gr., achíron es paja de techar, espata o chala; y nada tan parecido a esta última, como la hoja de la achira verde y seca. Según Dozy (Suppl. II, pág. 130, 1ª col.) los árabes del Mar Muerto dan el nombre de aschír a una planta que debe ser ribereña (v. más arriba la descripción de la que estudiamos). Asimismo, en ár., aschír significa bosquecillo, matorral (Íd., íd., II, 758, 1ª). Aaskschiru es el nombre berberisco de una planta sin especificación. (Íd., íd., I, 1, 2a); y aschíria el lirio blanco, semejante por sus hojas a la achira. (Íd., íd., I, 25, 1a). Creo probable, sin embargo, que el origen de estas voces sea el mencionado gr. aschiron, pues la región del Mar Muerto perteneció doscientos años al Imperio de los Seleucidas y al de los Tolomeos cuyo idioma oficial común fué el griego que continuó hablándose allá bajo la dominación romana; fuera de que, en latín, la antedicha voz gr. achíron, dió su nombre a la paja de techar: achyrum. La conquista arábiga de la Berbería fué efectuada por tropas procedentes de la misma región, y los árabes adoptaron en su botánica la nomenclatura griega.

Por otra parte, Plinio (Nat., Hist., XXVII, 20) describe dos plantas: el ascyron y el ascyroides (pronúnciase aschir-on, oides) muy semejantes, y la segunda de las cuales tiene el follaje rojo como nuestra achira vulgar, mientras sus ápices o sumidades dan, si de los rompe, un jugo de color rojo sanguíneo. Nuestra voz achira procede, pues, de esas dos, concurridas por achyrum: paja, que engendró el baj. lat. transitivo acira: planta semejante al puerro por las hojas, como la achira, precisamente. 
La etimología como gesto glotopolítico. El CASo del DiCCIONARIO ETIMOLÓGiCo DEL CASTELLANO USUAL (I93 I-I938) De LeOPOLdo LUGONES

achura. (s. e. D.). "f. Argent. Cualquier intestino o menudo del animal vacuno, lanar o cabrío".

Trátase de una evidente pronunciación vulgar de asadura, que es la misma cosa, y que el vulgo de España dice también asaúra. La constitución fonética de la voz, queda completa, si recordamos la pronunciación peninsular de la ese que debió resultar más silbada todavía, puesto que asadura no deriva de asado como el Dic. asienta, sino del lat. assatura: asado, cuya doble ese es chillante de suyo. Concurrieron seguramente a la formación de la voz que estudiamos las arábigas asschul: ganado, y aischul: ternero, por aféresis y permutación consonante a la vez, de chulla: posta de carne (s. e. D.) y de su derivado chuleta que, de consiguiente, no hay por qué atribuir al valenciano (v.). En su Historia Natural de las Indias (lib. VI, cap. 11) Oviedo, que era asturiano de origen y madrileño de nacimiento, denomina asadura al páncreas; por donde se ve que no se trata solamente de "lonjas" como asienta el Dic. (v.). En vascuence, a su vez, achuria es cordero y procede también de los árs. antedichos.

Achura hace, naturalmente, el verbo achurar cuyo artículo (v.) faltan nuestras aceps. metafóricas de herir en pelea y de ofender por sorpresa; mientras la acción de beneficiar la res, y quien la ejecuta, denomínanse churiar y churiador en castellano vulgar, aunque el Dic. no lo registre (v.). En jerga andaluza y en caló, chori y churi significan cuchillo. Advertiré, sin embargo, que desde en los primeros vocabularios quichuas como el de San Thomas (año de 1560) la voz achura designa en dicha lengua parte, pedazo, porción. Mas, por lo que se ha visto y verá, creo que se trata de un españolismo como tantos otros que aquellos libros consignan.

Por otra parte, chulo es peón de matadero ( $4^{\mathrm{a}}$ acep.) y ayudante en las plazas de toros ( $5^{a}$ acep.); todo lo cual explica las aceps. restantes de dicha voz (v.). Bajo la 2a: "individuo del pueblo bajo de Madrid, que se distingue por cierta afectación y guapeza en el traje y en el modo de producirse", llaman en todo el interior argentino, churo al gaucho apuesto, y por extensión a todo lo agraciado y garboso. No hay, pues, necesidad de recurrir al supuesto ár: chaul: joven, según la Academia, para la etimología de chulo que "no es de origen arábigo", según lo aclaró ya Dozy en el Suppl., I, 806; 1ª col., como tampoco significa chaul, o mejor dicho schul, lo que el Dic. quiere que sea en ár. (v.). La lengua provenzal suministra en cambio tres voces concluyentes para determinar la formación de la que estudiamos: chouro, chourlo y choulo, que designan al joven peón de granjas, molinos y telares, y que proceden del gr. 
koros, kouros (pronúnciase kuros): mozo, muchacho, peón, joven (v. Mistral, Lou Tresordóu Felibrige, ou Dictionnaire Provençal-Français, art. pertinente). Chulo, chula, explican, asimismo, a cholo y chola mestizos de indio y europeo, lo mismo en Méjico que en el Perú; por donde resulta destinada la etimología del Dic. "de Chollán, hoy Cholula, distrito de Méjico". (v.).

De la misma voz achura, por su procedencia de "asado", según la forma original: asadura, concurrida por los antedichos árs. asschuly aischul: ganado, ternero, proceden también churrasco, churrete, churretoso, churriento, churro, 1er. Art. (todas, también, s. e. D.). De ellas provienen igualmente siendo meras variantes formadas por analogía, chorro y sus nueve derivados (v.) a todos los cuales atribuye el Dic. la antojadiza procedencia del lat. susurrus, que significa solamente murmullo, ruido sordo o vago, zumbido; y por metáfora, calumnia, delación. Por último, churumo: jugo o sustancia, que asocia las aceps. de churre y churro (v.) confirmando la atribución.

Pero, aquí, por intermedio de chorrón: copo de cáńamo (v.) churro, $2^{\circ}$ art., en sus dos primeras aceps. de mechón de lana y el animal que lo lleva; chirumen y churumen: caletre, es decir, cabeza por metáfora (todos s. e. D.) hallamos una concurrencia interesante:

Chorrón y churro proceden del lat. círrhi: copete de ave, fleco, rizo de pelo influído por chorrera, y que en el Vocabulista del P. Alcalá, presenta la forma arábigo-española chirr: guedeja, asociada a su vez con el ár. scháar: crin. La voz lat. cirrhi y la arábigo-española chirr, concurridas por otra ár., rischa: pluma, dan el origen de rizo que, según el Dic., es el mismo de erizo (v.). Y de la misma forma chirr, salió nuestra designación campestre de chilla que el Dic. no registra: mechón de cerda o de lana (v.). Lo que sí concurrió a la formación de rizo, es el gr. frisso: erizar de espinas o de lanzas, y también alborotar la barba, el pelo, las plumas. De ahí salió, asimismo, frisa (v.) voz que la Academia cree derivada del anglo-sajón frise (?).

Chirumen, churumen, churumo: jugo, y caletre por metáfora, asócianse originariamente al lat. sérum: suero y jugo, zumo en general, que hizo los bajo lats. séru y serúmen: suero, rezumo, con influencia analógica de cacumen: agudeza, ingenio (v.). Las voces cerro y cirro, que significan respectivamente copo de cáñamo o de lino, y nubecilla crespa (ambas con etimologías erróneas en el Dic. (v.) tienen, pues el mismo origen que chorrón y que churro. Tenemos también en todo ello el origen de la voz chirle que para el Dic. significa, tan sólo, insípido, insustancial, aunque, propiamente, es aguachento, lo mismo que sirle, voz a la cual remite, y que significa plasta de estiércol de vaca y 
La etimología como gesto glotopolítico. El CASo del DiCCIONARIO ETIMOLÓGiCo DEL CASTELLANO USUAL (I93 I-I938) De LeOPOLdo LugONES

de oveja. Ambas voces, a su vez, relaciónanse directamente con churro: pringue, y churriento, según lo indica la forma sirria que el Dic. deriva del catalán (v.). Sabido es que la contracción de la $u$ en $i$ fué frecuente en toda la antigua Espańa. Trátase, pues, de una familia de veintiocho voces con triple origen concurrente greco-latino-arábigo, así como de otros tantos errores u omisiones etimológicas del Dic.

ampalagua. (V. $\mathrm{N}^{19}$ ). El Diccionario Argentino por Tobías Garzón (Barcelona, 1910) define correctamente y en todas sus formas este argentinismo que es necesario incluir, dada la importancia del animal que denomina: "Boa de la Rep. Arg. conocida entre nosotros con este nombre y los de lampalagua y ampalava. El Dic. de una Sociedad Literaria (año 1868) trae ampalaba. Se (sic) engulle vizcachas, comadrejas, zorros, etc. y hasta criaturas". La etimológica conjetural que transcribe el Tesoro de Catamarqueñismos de Lafone Quevedo es una fantasía disparatada [remite al idioma cacán]. Corresponde ańadir que se trata de la Boa constrictor; diviniloquis, y que su cuero es de mucho valor industrial.

La voz ampalagua, ampalava o lampalagua, completamente ajena a las lenguas indígenas, procede a mi ver del ár. afaguán: víbora macho, concurrido por otro ár., lafagáa: víbora, serpiente, pero en cuya formación han debido intervenir los verbos alampar, lampar: ansia de comer o beber como engullendo, y probablemente lamprea: gran pez de forma ofídica cuyo nombre, según lo estudio en el art. pertinente, procede del gr. amprón: coyunda; mas, carezco de los elementos necesarios para completar la formación.

apañado. $2^{\circ}$ art. "De apañar. 2. Hábil, mañosos para hacer alguna cosa. Adecuado, a propósito para el uso a que se destina". Y apañar: "De $a, 2^{\circ}$ art., y paño. Recoger y guardar alguna cosa. 2. Asir o recoger con la mano. 3 . Tomar alguna cosa, o apoderarse de ella, capciosa e ilícitamente. 4. Aderezar, asear, ataviar. 5. Abrigar, arropar. 6. Remendar o componer lo que está roto. 7. Darse mańa para hacer alguna cosa".

Falta la acep. argentina registrada por Tobías Garzón en su Diccionario Argentino (Barcelona, 1910; art. pertinente): "Tapar, encubrir o disculpar maliciosamente las picardías, travesuras o delincuencia del otro. Esconderlo u ocultarlo para que no lo castiguen". - que como veremos es apropiada y

19 Significa "Voz nueva", es decir, neologismo en relación con el DRAE. 
castiza. En el Perú, según lo consigna el mismo autor (loc. cit.) tiene la de "dar razones o pruebas que descarguen de una culpa", igualmente buena, como que es mera variante de la $7^{\mathrm{a}}$ de apañar que consigna el Dic., y de la $3^{a}$ de apaño: "disposición, mańa o habilidad para hacer alguna cosa".

Ahora bien, ni apañado, $2^{\circ}$ art., ni apañar en sus aceps. $1^{\mathrm{a}}, 2^{\mathrm{a}}, 3^{\mathrm{a}}$ y $7^{\mathrm{a}}$, así como en la argentina y la peruana que consigné, ni apaño en la $3^{\mathrm{a}}$, proceden de paño, según es evidente, sino de voces distintas y concurridas por otras que también lo son conforme vamos a verlo.

La principal es el baj. lat. apanáre, derivado del lat. panis: pan, y que significó dar, ofrecer, suministrar pan o alimentos cualesquiera; y por antífrasis, quitarlos, arrebatárselos a alguno. Así, apanágium, su acción y efecto, hizo el fr. apanage: tierra feudal dada en usufructo por la Corona; esta misma concesión y el derecho que ella creaba. Tanto en estas aceps. directas, como en la extensiva de favorecer, que hizo la antigua locución fr. apaner une fille: dotar una muchacha, apanare y apanagium son los orígenes de la $1^{\text {a }}$, $2^{\mathrm{a}}$ y $3^{\mathrm{a}}$ aceps. de apañar, así como de la nuestra, esencialmente; pero, ya en esta última, concurren a no dudarlo amañar y amaño, que con las suyas de "darse maña, acomodarse" y de "traza o artificio" (v.) predominan en la $2^{a}$ y $3^{\mathrm{a}}$ de apañado, en la $7^{\mathrm{a}}$ de apañar; en la peruana del mismo verbo, y en la $3^{a}$ de apaño. Apañar, $3^{\text {a }}$ acep., es, asimismo apañuscar (v.) lo cual remonta otra vez el baj. lat. apanagium(...).

A partir del recorte representativo reproducido, se advierten tres procedimientos a partir de los cuales el autor pone en juego la etimología con el propósito de refutar el origen indígena, quechua, aimara, guaraní, araucano, náhuatl, taíno, entre otras lenguas, de una serie de vocablos. Los argumentos a favor de la pureza y del casticismo, tan caros al ideal decimonónico, están detrás del planteo, como se vio, y motivan el resurgimiento del interés por los orígenes ya sean remotos, ya sean más inmediatos de las palabras. 
La etimología como gesto glotopolítico. El CASo del DiCCIONARIO ETIMOLÓGiCo DEL CASTELLANO USUAL (I93 I-I938) De LeOPOLdo

Un primer caso, no muy numeroso a lo largo de la obra, pero, sin dudas, significativo es el de la voz abatí en cuyo breve comentario lingüístico se declara fehacientemente la inexactitud de la etimología de origen guaraní propuesta por la Academia, pero no se ofrecen datos ni siquiera sucintos o mínimos que permitan desplegar algún tipo de fundamentación para dar cuenta de ese planteo. El origen de la voz, asegura Lugones, es incierto.

El segundo tipo de mecanismo, también poco numeroso, consiste en formular etimologías del tipo de las denominadas condicionales, como se aclaraba en la Advertencia del diccionario. Tal es, por ejemplo, el caso de la voz acal, en donde la explicación etimológica y, por consiguiente, la búsqueda del origen del vocablo se enuncia mediante expresiones modalizadas del tipo "permiten suponer" y/o verbos en modo condicional como "sería”. Es la modalidad lógica de la duda la que prevalece en estos enunciados.

El tercer y último mecanismo es el más recurrente y atractivo para el análisis. Se trata, en algunos casos, menos de artículos lexicográficos breves y puntuales que de textos monográficos metalingüísticos bastante extensos (ver achura), con tramos digresivos que se enfocan en términos distintos al lema en cuestión, con abundante (incluso, en ocasiones, exagerada) cantidad de datos no siempre pertinentes y con asociaciones etimológicas forzadas que rozan el absurdo en ciertos pasajes ${ }^{20}$.

20 Se corroboró en el Breve diccionario etimológico de la lengua castellana de Joan Corominas ( $3^{\text {a }}$ edición, 1973, Madrid, Gredos) que las voces consideradas "falsos indigenismos" de acuerdo con Lugones, tienen, en rigor, procedencia indígena. Por otro lado, la mayoría de los diccionarios actuales no portan el componente etimológico debido a que registran únicamente el léxico en uso. Cfr.: Carriazo Ruiz (2014). 
La singular estructura textual de esta clase de artículos consiste en marcar, en primera instancia, la etimología errónea consignada en el $D R A E$, principal intertexto de contrastividad. Luego, la secuencia apunta a acusar (censurar, incluso, a veces, recurriendo a la ironía) a la Academia de copiar equivocadamente las etimologías indígenas de los diccionarios de -ismos sean estos provinciales (catamarqueñismos), nacionales (argentinismos, chilenismos, mexicanismos), regionales (rioplatense) o de americanismos. Como dijimos, el repertorio de Lenz (voz achiguarse) es muy citado para la impugnación de la historia de la voz en cuestión al igual que el de Garzón para los argentinismos (voces ampalagua y apañado). El último paso del esquema argumentativo radica, a partir de la inclusión de un conector adversativo del tipo "pero" o "mas", en presentar la (re)interpretación propia y asignar, por consiguiente, a dichos vocablos etimologías provenientes, en general, del árabe, latín (o bajo latín) o griego, no sin antes ofrecer comparaciones (de palabras o de raíces) con distintas lenguas romances (castellano medieval, provenzal, catalán, francés, italiano, portugués, rumano). De los ejemplos citados, se ajustan a este patrón de procedimiento acochinar, achiguarse, achira, achura, como así también un conjunto de voces tales como agutí, aji, alpaca, que, por un tema de extensión, no son transcriptos en el presente artículo.

\section{COnClusiones}

La reflexión sobre las posiciones respecto de la lengua en términos de hegemonía implica explorar en zonas del archivo el lugar de los intelectuales 
La etimología como gesto glotopolítico. El Caso del DiCCIONARIO ETIMOLÓGiCo DEL CASTELLANO USUAL (I93 I-I938) De LeOpoldo LUGONES

en tanto organizadores de la cultura. Al igual que el de los lingüistas y los gramáticos, el discurso de otros agentes culturales que operan en los procesos de construcción de lo hegemónico en materia lingüística (críticos literarios, escritores, profesores, periodistas, filólogos y lexicógrafos) debe ser leído en torno a lo que se entiende como lengua legitima (Bourdieu, 2008) en el marco del juego histórico de las disputas por sus sentidos, a través de sus alcances, límites, regímenes de argumentación, inclusiones y exclusiones. En particular, los discursos metalingüísticos como los diccionarios y otros repertorios lexicográficos, al tratar cuestiones sobre el léxico, diseñan simultáneamente representaciones sobre la nación y sobre el universo social en su conjunto que se pretende configurar en un determinado momento.

La intervención glotopolítica de Lugones está al servicio de una causa y de los intereses que esta promueve. En este sentido, su proyecto de diccionario etimológico es un dispositivo político, lingüístico y pedagógico (por el lugar material en el que se publica: la prensa gráfica dedicada a maestros) de disciplinamiento potente para destacar lo propio, ordenar y jerarquizar desde la lengua la sociedad argentina, dejando de lado las lenguas indígenas, pero también las expresiones y modos de decir bárbaros de los extranjeros inmigrantes y a los vulgares y populares de ciertos grupos sociales. $\mathrm{Al}$ mismo tiempo, toma distancia de la matriz hispanista, académica, que quiere conservar una lengua pura. Para cumplir con esa misión "patriótica” acudió a un engranaje de conjeturas etimológicas, por momentos, muy ingeniosas y hasta disparatadas. Pese a que se presentan en el cuerpo de los artículos del diccionario una serie de datos ordenados, buscando un efecto de exhaustividad 
y cientificidad, con un estilo comprensible y con un tono pedagógico, los razonamientos carecen del tipo de fuentes documentales esperables en trabajos rigurosos desde una perspectiva científica. Se trata, en definitiva, de especulaciones poco fundadas y con escaso rigor metodológico. El recurso de la etimología opera, en efecto, como el argumento central (el principio de autoridad, podríamos decir) que le permite a Lugones fijar los orígenes de la cultura argentina en un momento identificable, pero, a la vez, ajeno y remoto. Desde un punto de vista socio-histórico más amplio, en el que las intervenciones sobre el lenguaje y la lengua inevitablemente se inscriben, la vuelta al origen, en el contexto del primer golpe militar de la historia, se lee en términos de restauración de un orden social, económico y político esencial y verdadero, frente al progresivo avance, en términos políticos, económicos, sociales y, por supuesto, también lingüísticos de los sectores subalternos.

\section{REFERENCIAS BIBLIOGRÁFICAS}

Alcobre, Mariana. "El Monitor de la Educación Común como gestor de políticas públicas antiliberales (1932-1938)". Ponencia presentada en International Standing Conference for the History of Education, Buenos Aires, Argentina, 2017, s/p.

Alvar, Manuel. "Nuestros primeros diccionarios etimológicos”. In: Quirós García, Mariano et al. (eds.). Etimología e historia en el léxico español. Madrid-Frankfurt: Iberoamericana-Vervuert, 2016, 39-56.

Angenot, Marc. El discurso social. Buenos Aires: Siglo XXI Editores, 2010.

Arnoux, Elvira N. de. Análisis del discurso. Modos de abordar materiales de archivo. Buenos Aires: Santiago Arcos, 2006. 
La etimología como gesto glotopolítico. El CASo del DiCCIONARIO ETIMOLÓGiCo DEL CASTELLANO USUAL (I93 I-I938) De LeOPOLdo

Arnoux, Elvira N. Los discursos sobre la nación y el lenguaje en la formación del Estado (Chile, 1842-1862). Estudio glotopolítico. Buenos Aires: Santiago Arcos, 2008.

Auroux, Sylvain. A revolução tecnológica da gramatização. Campinas: UNICAMP, 1992.

Auroux, Sylvain. A questão da origem das linguas, seguido de A historicidade das ciências. Campinas: RG Editora, 2008.

Barcia, Pedro Luis. Los diccionarios del español de la Argentina. Buenos Aires: Academia Argentina de Letras, 2004.

Bentivegna, Diego. "Estilo, metáforas, indicios: Lugones y sus posiciones frente a la lengua entre los dos siglos". In: Díaz, Valentín (ed.). Episodios críticos de la modernidad latinoamericana. Sáenz Peńa: Eduntref, 2017, 17-28.

Bentivegna, Diego. "Formar la lengua. Etimología, patria y lenguaje en El payador de Leopoldo Lugones". In: Interpretatio, 3, 1, 2018, 139-162.

Bertoni, Lilia Ana. Patriotas, cosmopolitas y nacionalistas. La construcción de la nacionalidad argentina a fines del siglo XIX. Buenos Aires: Fondo de Cultura Económica, 2001.

Bourdieu, Pierre. ¿Qué significa hablar? Madrid: Akal, 2008.

Branca-Rossof, Sonia. "La construction de la norme lexicographique à la fin du 18ème siècle: Féraud le médiateur". In:Mazière, Francine (ed.). La genèse de la norme. París: SHESL, 1995, 34-46.

Branca-Rossof, Sonia. "Guerre de religion et guerre sainte dans les dictionnaires français”. In: Mots, 50, 1997, 151-156.

Carriazo Ruiz, José Ramón. "Los indigenismos en el Diccionario crítico etimológico castellano e hispánico de Joan Corominas y José Antonio Pascual”. In: EPOS, XXX, 2014, 147-160.

Carriazo Ruiz, José Ramón. “Diccionarios etimológicos”. In: Estudios de Lingüística del español, 38, 2017, 7-33. 
Cattaruzza, Alejandro. Historia de la Argentina. 1916-1955. Buenos Aires: Siglo XXI, 2009.

Celada, María Teresa, Michele Costa \& Daniela Brianezi. "Sobre el funcionamiento de ciertos preconstruidos en los títulos de diccionarios de lengua española. Las marcas de una historia”. In: Linguas e Instrumentos Linguísticos, 36, 2015, 267-291.

Collinot, André y Francine Mazière. Un prêt à parler: le dictiónnaire. París: PUF, 1997.

Devoto, Fernando. Nacionalismo, fascismo y tradicionalismo en la Argentina moderna. Una historia. Buenos Aires: Siglo XXI Editora Iberoamericana, 2005.

Del Valle, José. “Lenguaje, política e historia: ensayo introductorio”. In: Del Valle, José(ed.). Historia política del español. La creación de una lengua. Madrid: Aluvión, 2015, 3-23.

Di Tullio, Ángela. Politicas lingüisticas e inmigración. Buenos Aires: Eudeba, 2003.

Forgas Berdet, Esther. "Diccionarios e ideología”. In: Interlingüistica, 17, 2007, 2-16.

Funes, Patricia. Salvar la nación. Buenos Aires: Prometeo, 2006.

Glozman, Mara y Daniela Lauria. Voces y ecos. Una antología de los debates sobre la lengua nacional (Argentina, 1900-2000). Buenos Aires: Cabiria y Biblioteca Nacional, 2012.

Guiraud, Pierre. L'étymologie. París: PUF, 1979.

Lara, Luis Fernando. Teoría del diccionario monolingüe. México: El Colegio de México, 1997.

Lauria, Daniela. "Apuntes para una historia de la producción lexicográfica monolingüe en la Argentina: etapas del proceso de diccionarización y modalidades diccionarísticas entre 1870 y 1910”. In: Boletín de Filología, 1, XLVI, 2011, 105-151. 
La etimología como gesto glotopolítico. El CASo del DiCCIONARIO ETIMOLÓGiCo DEL CASTELLANO USUAL (I93 I-I938) De LeOPOLdo

Lauria, Daniela. "La Academia Argentina de Ciencias y Letras y su posición sobre la lengua nacional (1873-1879)”. In: PRISMAS, 16, 2012, 171-174.

Lauria, Daniela. "Lengua nacional, inmigración y disciplinamiento en el Vocabulario argentino: neologismos, refranes, frases familiares, etc. usados en la Argentina de Diego Díaz Salazar (1911)”. In: Diálogo de la Lengua, VII, 2015, 1-21.

Lauria, Daniela. "Lengua y nación: implicancias glotopolíticas del proyecto del Diccionario de argentinismos de la Academia Argentina de la Lengua (1910)". In: Bein, Roberto, Juan Eduardo Bonnin, Mariana di Stefano, Daniela Lauria y María Cecilia Pereira (coords.). Homenaje a Elvira Arnoux. Estudios de análisis del discurso, glotopolitica y pedagogía de la lectura y la escritura. Tomo II: Glotopolítica. Buenos Aires: Editorial de la Facultad de Filosofía y Letras, Universidad de Buenos Aires, 2017, 111-128.

López, María Pía. Lugones: entre la aventura y la Cruzada. Buenos Aires: Colihue, 2004.

Lugones, Leopoldo. El payador. Tomo Primero El hijo de la pampa. Buenos Aires: Otero \& Co. Impresores, 1916.

Lugones, Leopoldo. Diccionario etimológico del castellano usual. Buenos Aires: Academia Argentina de Letras, 1944.

Lugones, Leopoldo. Didáctica, en El payador y antología de poesía y prosa. Caracas: Biblioteca Ayacucho, 1979.

Mazière, Francine. "Le dictionnaire deshabillé par ses préfaces". In: Lexique, 3, 1986, 33-45.

Medeiros, Vanise. "Um glossário contemporâneo: a língua merece que se lute por ela.”. In: Rua, 18, 2012, 19-34.

Nunes, José Horta. "Dicionarização no Brasil: condições e processos”. In: Nunes, José Horta y Margarida Petter (orgs.). História do saber lexical e constituição de um léxico brasileiro. Campinas: Pontes, 2002, 99-120. 
Nunes, José Horta. Dicionários no Brasil: análise e história do século XVI ao XIX. Campinas: Pontes, 2006.

Petri, Verli. "Gramatização das línguas e instrumentos linguísticos: a especificidade do dicionário regionalista”. In: Linguas e Instrumentos Linguísticos, 29, 2012, 23-37.

Rodríguez Barcia, Susana. La realidad relativa. Evolución ideológica en el trabajo lexicográfico de la Real Academia Española (1726-2006). Vigo: Publicaciones de la Universidad de Vigo, 2008.

Rodríguez Barcia, Susana. "El componente ideológico en la historia de la lexicografía monolingüe española”. In: Encinas Manterola, María Teresa et al. (comps.) Ars Longa, diez años de AJIHLE. Buenos Aires: Voces del Sur, 2010, 383-394.

Rodríguez Barcia, Susana. "El análisis ideológico del discurso lexicográfico: una propuesta metodológica aplicada a diccionarios monolingües del español”. In: Verba, 39, 2012, 135-159.

Rodríguez Barcia, Susana. Introducción a la lexicografía. Madrid: Síntesis, 2016.

Terán, Oscar. Historia de las ideas en la Argentina. Buenos Aires: Siglo XXI, 2008. 